\title{
Distribution of Glycine Receptors on the Membrane of a Central Neuron: An Immunoelectron Microscopy Study
}

\author{
Tania Seitanidou, Antoine Triller, and Henri Korn \\ Laboratoire de Neurobiologie Cellulaire, INSERM U261, Département des Biotechnologies, Institut Pasteur, 75724 Paris \\ Cédex 15, France
}

The distribution of glycine receptors on the plasmalemma of the teleost Mauthner cell was examined with light and electron microscopy using monoclonal antibodies raised against the glycine receptors of the rat. These immunoglobulins recognize a peptide of $93 \mathrm{kDa}$ associated with the intracellular side of the receptor complex. With indirect immunofluorescence, labeling appeared as small clusters over the whole surface of the neuron. This distribution indicates that, unlike other neurons, the Mauthner cell can express glycine receptors at the dendritic and at the somatic level as well. Vestibular or reticular neurons lying in the proximity of the Mauthner cell were also stained.

At the ultrastructural level, the immunoenzymatic reaction product, localized in front of the presynaptic active zones, slightly overextends the limits of the synaptic complex. This observation may account for vesicular exocytosis at the border of the presynaptic grid. More generally, inside and outside the axon-cap, stained postsynaptic membranes were apposed to terminals identified as unmyelinated club endings and some small vesicle boutons, respectively. Each of them could establish classical flat synapses or spinelike contacts, the latter being described here for the first time. Patches of membrane remained unstained, however, particularly along the lateral and ventral dendrites of the cell; they corresponded to the contact sites of excitatory afferents. In order to enhance the penetration of immunoreactive substances, a particular fixation procedure was used; its effect on the shape of the synaptic vesicles is described.

Our results support the notion that glycine is responsible for both somatic and remote dendritic $\mathrm{Cl}^{-}$-dependent inhibition of the Mauthner cell. The first one is produced by the so-called PHP exhibiting neurons, which correspond to cells of recurrent collateral network and vestibulovestibular pathway. In contrast, cells giving rise to the more distal inhibitory synapses on both dendrites are not yet characterized.

\footnotetext{
Received Dec. 10, 1987; revised Mar. 14, 1988; accepted Mar. 18, 1988.

We thank H. Betz (Zentrum für Molekulare Biologie, Heidelberg) for providing us with the monoclonal antibodies, Jean-Claude Waeselynck for computer assistance, and Helen Korn for help with photographic work. This research was supported by grants from the Ministère de la Recherche et de la Technologie (MRT $85 \mathrm{Cl141}$ ) and from the Communauté Economique Européenne (Contrat ST2 0400).

Correspondence should be addressed to Tania Seitanidou, Laboratoire de Neurobiologie Cellular, INSERM U261, Institut Pasteur, 25 rue du Docteur Roux, 75724 Paris Cédex 15.
}

Copyright (C) 1988 Society for Neuroscience $0270-6474 / 88 / 114319-15 \$ 02.00 / 0$
Glycine is a major inhibitory neurotransmitter in the CNS of many species (Werman et al., 1967, 1968; Aprison and Daly, 1978) and is involved, for instance, in the genesis of the recurrent collateral inhibition of spinal motoneurons in vertebrates (Eccles et al., 1954; Brooks and Wilson, 1959; Larson, 1969). Receptors for this amino acid are found primarily in the phylogenetically oldest parts of the CNS (Aprison et al., 1969; Zarbin et al., 1981); thus, they have a nonuniform distribution in the CNS.

Until recently, the morphological evidence for glycinergic transmission was obtained with biochemical and indirect autoradiographic methods: (1) Glycinergic boutons were identified using tritiated glycine to localize its high-affinity uptake sites in the spinal cord (Hökfelt and Ljungdahl, 1971), in the cerebellum (Wilkin et al., 1981), and in the retina (Pourcho, 1980; Cohen and Sterling, 1986); (2) the receptor distribution was detcrmined from ${ }^{3} \mathrm{H}$-strychnine binding in the brain (Palacios et al., 1981; Zarbin et al., 1981; Frostholm and Rotter, 1985; Probst et al., 1986). The labeling obtained with this alkaloid is due to its specific interaction with the glycine receptor (Young and Snyder, $1973,1974)$, the localization of which was, however, not possible with this method at a subcellular level. The production of monoclonal antibodies raised against the isolated glycine receptor (Pfeiffer et al., 1984) has allowed a more accurate immunocytochemical demonstration with both light and electron microscopy that postsynaptic receptors for glycine are present in the CNS. They showed that, at the ultrastructural level, the determinants recognized by the antibodies are detected at restricted sites facing the presynaptic active zones in the spinal cord, brain stem, and cerebellum of the rat (Altshuler et al., 1986; Triller et al., 1985, 1987b).

Inhibitory synapses are often believed to be the dominant somatic input (Eccles, 1969), but dendritic inhibition has also been described in many instances (Granit et al., 1964; Alger and Nicoll, 1982). Yet the exact distribution and fine structure of receptors to specific transmitters remain unknown. The Mauthner (M-) cell of the teleosts is a suitable model for approaching this problem. First, this neuron and its processes are identifiable morphologically (Bartelmez, 1915). Second, electrophysiological experiments have shown that iontophoretically applied glycine induces a strychnine-sensitive and chloride-dependent conductance (Furukawa et al., 1964; Diamond et al., 1973; Faber and Korn, 1982). Third, some of the inhibitory afferents of the M-cell have been characterized electrophysiologically (Faber and Korn, 1973; Korn and Faber, 1976) and visualized using intracellular staining with Procion yellow (Korn and Faber, 1975b) or with HRP (Korn et al., 1978; Triller and Korn, 1981, 1982). 
They belong to 2 groups of interneurons: the commissural (Triller and Korn, 1981) and those of the recurrent collateral network (Triller and Korn, 1978, 1982). A large proportion of their endings enters the so-called axon-cap (a peculiar structure surrounding the initial part of the M-cell's axon), where they terminate either on small dendrites within this area or directly on the somatic membrane of the cell. Other terminals bypass this region and impinge dircetly on the soma outside the axon-cap and on the initial part of its principal ventral and lateral dendrites (Triller and Korn, 1986). These and physiological data (Diamond et al., 1973; Faber et al., 1983) indicate that somatic inhibition produced in the M-cell after stimulation of these interneurons is glycinergic. This amino acid may also be responsible, along with GABA, for remote dendritic inhibition of the Mauthner cell (Diamond, 1968).

The morphology of the presynaptic endings on this neuron has been described in detail by Nakajima (1974), who recognized 6 main categories of terminals. The endings of the abovementioned vestibular or collateral interneurons belong to 2 of these classes: the unmyelinated club endings (UCEs) and the small vesicle boutons (SVBs), located in and outside the axoncap, respectively (Triller and Korn, 1981, 1982). Whatever their location, both types of junctions contain pleiomorphic vesicles after aldehydic fixation and form asymmetrical or Gray type II synapses (Gray, 1959), with a prominent dense material in the synaptic cleft.

In this study, the subsynaptic distribution of the glycine receptors was probed with 2 monoclonal antibodies (mAbs), GlyR5a and GlyR7a, which recognize the $93 \mathrm{kDa}$ polypeptide, a peripheral protein associated with the glycine receptor complex (Pfeiffer ct al., 1984; Schmitt ct al., 1987). It was found earlier that in the rat CNS this peptide has the same cytological distribution (Triller et al., 1987b) as that of mAb GlyR2b, which recognizes the $48 \mathrm{kDa}$ polypeptide bearing the strychnine binding site (Pfeiffer et al., 1984).

We report here that almost all UCEs and a great number of SVBs are apposed to glycine receptors. The density of the labeled SVBs is higher on the lateral than on the ventral dendrite and on the soma. In all cases, the immunoreactivity is concentrated at the level of the synaptic complex, regardless of its size, which varies in relation to the region of the cell where it is located.

Only some aspects of this study, which are analyzed here in detail, have been presented previously in preliminary short notes (Triller et al., 1986, 1987a).

\section{Materials and Methods}

Goldfish (Carassius auratus), $10-12 \mathrm{~cm}$ in length, were perfused through the heart with aldehydic fixative after anaesthesia with tricaine, MS222.

Fixation procedure. For light microscopy, animals were perfused with $4 \%$ paraformaldehyde (PFA) in $120 \mathrm{MM}$ phosphate buffer (PB) at a $\mathrm{pH}$ 7.4 for $30 \mathrm{~min}$ at $4^{\circ} \mathrm{C}$. After dissection, the brains were immersed overnight in $40 \%$ sucrose in $120 \mathrm{MM}$ PB at $4^{\circ} \mathrm{C}$ and sectioned the following day with a freczing microtome. Slices (60 $\mu \mathrm{m}$ thick) were dipped in $0.25 \%$ ammonium chloride in PBS to block the free aldehyde groups.

For electron microscopy, 2 different fixation procedures were employed: a classical one, allowing comparison with data from the literature, and a modified one in order to improve tissue preservation and penetration of the antibodies.

In the first case, a classical mixture of $4 \%$ PFA and $0.1 \%$ glutaraldehyde (GA) in $120 \mathrm{MM}$ PB, pH 7.4, was passed through the aorta for $25 \mathrm{~min}$, followed by $4 \%$ PFA alone, aimed at removing the unreacted GA. After overnight incubation in 4\% PFA in PB (120 $\mathrm{MM}, \mathrm{pH} 7.4)$, the brains were sectioned with a Vibratome, and the slices were sub- sequently reacted for $30 \mathrm{~min}$ with $0.1 \mathrm{MM}$ lysine in PBS

In a second set of experiments, the perfusion procedure had 3 steps. First, the goldfishes were perfused with the same 2 mixtures as above; then, as a last step, 4\% PFA in $0.12 \mathrm{~m}$ sodium bicarbonatc, $\mathrm{pH} 10.4$, was passed for $10 \mathrm{~min}$. At this $\mathrm{pH}$, the $\mathrm{N}$-terminal amino groups and the side-chain groups of the lysine residues are in the $\mathrm{NH}_{2}$ form, which renders the proteins more reactive with formaldehyde (Berod et al., 1981). This procedure will be referred to in the text as the "pH 10.4 fixation." In this case, the brains were dissected and kept in the basic fixative overnight at $4^{\circ} \mathrm{C}$. After being sectioned $(50 \mu \mathrm{m})$ with a Vibratome in cold $120 \mathrm{MM}$ PBS also containing $4 \%$ sucrose and $0.15 \mathrm{M} \mathrm{CaCl}_{2}$, the slices were dipped in 1\% sodium borohydride in PB for $30 \mathrm{~min}$ in order to block the unreacted aldehydic groups (Leenen et al., 1985).

Immunocytochemistry. For light and electron microscopy GlyR5a and GlyR7a were diluted in PBS at 1:50 and 1:100, respectively. For immunofluorescence, the sections were incubated with the primary antiserum overnight at room temperature in the presence of $0.25 \%$ Triton$X 100$ and $0.12 \%$ gelatin. After extensive rinsing with PBS, a sheep anti-mouse IgG antibody conjugated with the chromophore tetramethyl rhodamine isothiocyanate (SAM-TRITC) and diluted in PBS (1:200) was applied and reacted for $2 \mathrm{hr}$ at room temperature. The slices were mounted with Mowiol (Hoechst, Frankfurt) and examined with a Zeiss microscope equipped for fiuorescence.

The Vibratome sections were processed for electron microscopy. In order to increase the permeability of the antibodies in the tissue, the slices were run in ascending and descending series of ethanol solutions at $10,25,40,25$, and $10 \%$ in $\mathrm{PB}$ containing $0.15 \% \mathrm{CaCl}_{2}$ and $4 \%$ sucrose at $4^{\circ} \mathrm{C}$. This step was omitted when $4 \%$ PFA and $0.1 \%$ GA were only used as perfusion fixatives. The primary $\mathrm{mAb}$ was added after rinsing the tissue with PB and left to react overnight at room temperature. BSA (1\%) was used for blocking the nonspecific sites.

The Vectastain (Vector Laboratories, Inc., Burlingame, $\mathrm{C} \Lambda$ ) avidinbiotin-peroxidase complex (ABC) procedure (Hsu et al., 1981) was chosen to visualize the mAbs bound to the tissue. The avidin-biotin-peroxidase complex was revealed after addition of $0.03 \%$ diaminobenzidine

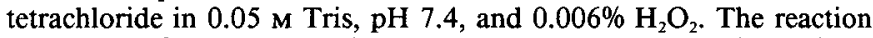
time varied from 5 to $15 \mathrm{~min}$ and was controlled under a light microscope. The slices were then postfixed with $2 \%$ osmium tetroxide in $\mathrm{PB}$ $0.14 \mathrm{M}$, dehydrated in graded ethanol, and flat-embedded in Araldite. Ultrathin sections were counterstained with a Reynolds solution, $\mathrm{pH}$ 12, (Reynolds, 1963) before examination with a Philips (CM10) electron microscope.

\section{Results}

\section{Immunofluorescent staining}

Light microscopic observations already showed that glycine receptors are widely distributed over the M-cell membrane, as illustrated in Figure 1, $A$ and $B$, for both GlyR5a and GlyR7a. They reveal a grainy image of the M-cell contour, with the degree of labeling varying according to the cellular locus. Stained somatic membrane inside the axon-cap was observed in a transverse plane (Fig. 1, $A, B$ ). Although in this area the cap-dendrites were faintly outlined, it was difficult to distinguish whether labeled receptors were also present on their surface because of the background autofluorescence. However, in certain cases the staining on these dendrites stood out above this background; it then appeared in the form of small spots on their surfaces. They are not illustrated here because they faced rapidly. On the other hand, the small ventral dendrites (Fig. 1, $A, B$, smaller arrows), also arising from the soma but outside the axon-cap, exhibited a clear dotted immunofluorescence.

The 2 principal dendrites of the M-cell, lateral and ventral, have antigenic determinants that are recognized by the $2 \mathrm{mAbs}$ (Fig. $1 C-F$ ) and are distributed over their entire membrane. For both neurites, the labeling extended beyond their terminal bifurcations up to their tips, which is at the level of the vestibular and the reticular nuclei, respectively. With high magnification, it appeared that the staining was discontinuous and delineated 
the surface of the cell. The spots were irregular in shape and in size and left free spaces between them, as illustrated in Figure $1 D$. This patchy appearance was even more dramatic on the distal part of the lateral dendrite viewed tangentially (Fig. 1, $E$, $F$ ). In this case, immunoreactive dots provided a negative image of circular spaces, which are approximately $12 \mu \mathrm{m}$ in diameter. This size corresponds to that of the large excitatory terminals that contact this distal part of the dendrite (Nakajima, 1974).

Other structures were also labeled in the brain stem of the goldfish by the mAbs, including cells of different sizes within the vestibular or the reticular nuclei (Fig. 2). Fluorescent patches were present on vestibular neurons in all nuclei of the complex. Cells from 2 of them, the lateral and the medial vestibular nuclei (Tello, 1909), are illustrated in Figure $2 A$, obtained in the vicinity of the tip of the lateral dendrite. The former nucleus is characterized by the large Deiters neurons, which were well stained in our material. As in the case of the M-cell, the labeling of the vestibular neurons was discontinuous and restricted to the cell surface at the soma and at dendritic extensions as well (Fig. 2, B, C). Again, the dots were irregular in size and in shape (Fig. 2C). The immunoreaction was also present on almost all reticular neurons encountered in this region, that is, on small bipolar cells (Fig. $2 D$ ) and on very large ones (Fig. 2, $D, E$ ). The labeling on the small cells was not different from that observed in the vestibular complex (Fig. 2, $D$ versus $B$ ) but on larger ones, the spots were smaller and more evenly distributed (Fig. $2 E$ ).

One should stress that, as a control, the first antibodies were omitted in same experiments, a procedure that resulted in the total absence of the specific fluorescence described above. Similar controls were also negative at the ultrastructural level.

\section{Electron microscopy results}

Data concerning the ultrastructure of terminal boutons apposed to glycine receptor-like immunoreactivity were obtained using the $\mathrm{pH} 10.4$ fixation procedure (see Materials and Methods). This approach was preferred because it improves the quality of fixation and enhances the penetration of immunoreactive substances. The effect of this technique on some morphometrical parameters of terminals is described here as well.

In all instances, the immunoenzymatic reaction product was associated with the cytoplasmic side of the plasma membrane facing synaptic contacts. In addition, electron-dense precipitate was sometimes also observed: (1) on adjacent plasma membrane extending beyond the limit of these synaptic complexes and (2) on nearby cellular organelles, such as microtubules, mitochondria, and endoplasmic reticulum.

\section{Labeling of the Mauthner cell within the axon-cap}

Labeled synaptic complexes were found in the peripheral part of the axon-cap, at the level of the axon hillock (Fig. $3 \mathrm{~A}-\mathrm{C}$ ) and on cap-dendrites (Fig. 3D-G).

Two adjacent stained terminals exhibiting the morphological characteristics of UCEs are shown in Figure $3 \mathrm{~A}$; a high-magnification view is given in Figure $3 B$. The reaction product is concentrated in front of a presynaptic active zone, where 2 exocytotic figures have been captured. In this case, which corresponds to $\mathrm{UCE}_{2}$ of Figure $3 A$, the electron-dense immunoprecipitate overextends the limit of the presynaptic active zone and faces progressively on the perisynaptic membrane. Junctions with this appearance will be referred to as "flat" synapses, since their synaptic complex itself is either flat or, at most, slightly convex. They contrast with another type of contact that is also present in the M-cell but which, to our knowledge, has not been reported at this level. In this last case, the labeled postsynaptic membrane is engulfed in the presynaptic element (Fig. $3 C$, see also Fig. 6). More conventional UCEs were also apposed to glycine receptors on cap-dendrites, as seen on the longitudinal section of Figure $3 \mathrm{D}$, where patches of labeled membrane left large portions of dendritic plasmalemma devoid of immunological reaction between them. A higher-magnification view (Fig. $3 E$ ) of the lowermost junction illustrated in Figure $3 D$ shows that the presynaptic element contained a pleiomorphic population of synaptic vesicles (see also below).

Finally, postsynaptic differentiations were also stained on capdendrites, as illustrated on a transverse section of one of them (Fig. $3 F$ ). In general, these immunopositive junctions left between them membrane free of staining in most cases, although in rare instances, the immunoprecipitate was present at perisynaptic portions of the membrane, giving the appearance of continuous labeling, linking between them post-synaptic differentiations. This is illustrated in Figure $3 G$, where the stained distance between adjacent synapses is as large as about $300 \mathrm{~nm}$.

\section{Labeling on the $M$-cell soma and dendrites outside the axon-cap}

Confirming immunofluorescent observations at the light microscopic level, the membrane of the M-cell was stained outside the axon-cap. Immunoprecipitate was found in front of the socalled SVBs, easily recognized by their pleiomorphic population of vesicles (Figs. 4-6). These endings contact the target cell within its synaptic bed, a myelin-free zone (5-10 $\mu \mathrm{m}$ wide), which contains only axon terminals and which is limited by a continuous layer of astrocytic processes. As exemplified in Figure $4 A$, some SVBs were apposed to nonstained synaptic membrane (crossed arrow), but they were few in number compared with the total population of such junctions. The proportion of stained synaptic contacts (Figs. $4 A$, arrow, and $4 B$ ) was estimated only from surface sections because of the irregular penetration of the antibodies in deeper areas of the blocks. In this manner, no less than $63 \%$ of the total number $(n=304)$ of synaptic complexes belonging to SVBs were found to be immunoreactive on the soma, $61 \%$ on the lateral dendrite $(n=$ $304)$, and $64 \%$ on the ventral one $(n=173)$. Labeled synapses were also encountered on small dendrites issued from the ventral region of the M-cell soma (Fig. 4C). It should be mentioned that some SVBs apposed to immunoreactivity (Fig. $4 D$, arrow) were adjacent to terminals, here a small myelinated club ending, which established with the target cell both chemical synaptic contacts (crosscd arrow) and gap junctions (arrowhead), thus achieving a so-called mixed synapse. The chemical components of such contacts were most often located at the periphery of the terminals and in close proximity to the neighboring stained receptors, in a manner favoring interactions between the 2 types of boutons judging at least from a morphological point of view.

The electron microscopic observations indicated that the labeled patches of membrane of the principal dendrites were directly in front of the active zones of the presynaptic boutons, identified again as SVBs, which, at the level of the lateral dendrite, were comparable to those impinging on the M-cell's soma (Fig. 5A). Most of them were, however, larger than those observed at the somatic level (see below). Quite often, these endings were adjacent to small (Fig. 6B) and/or large myelinated club endings; it thus can be ascertained that the circular patches of membrane devoid of labeling, noted at the light microscopic 

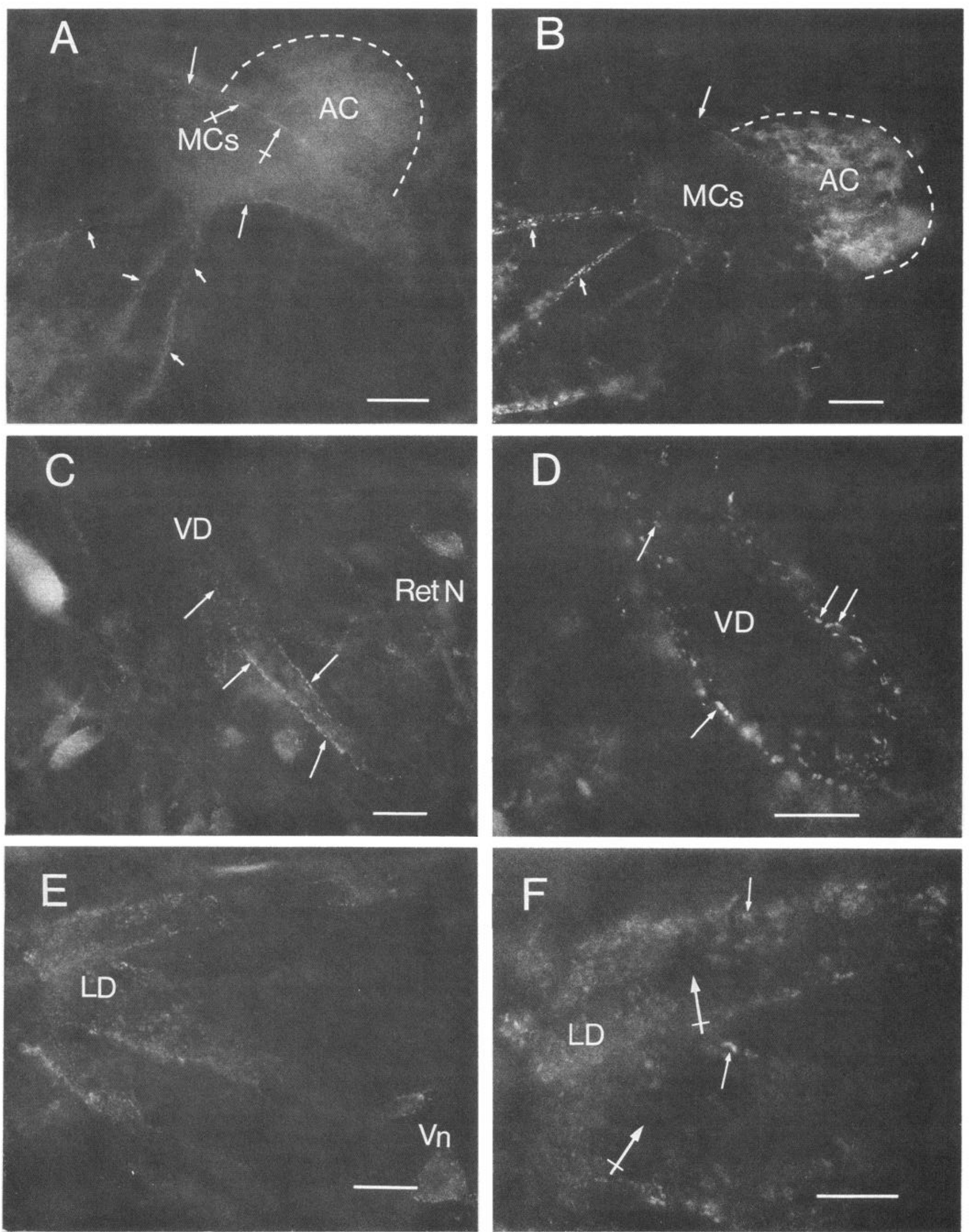

Figure 1. Visualization of the glycine receptor on the M-cell plasma membrane; indirect immunofluorescence using monoclonal antibodies GlyR5a and GlyR7a. $A$ and $B$, Two different M-cells labeled with GlyR5a $(A)$ and with GlyR7a $(B)$. Fluorescence is present outside (large arrows) and inside (crossed arrows) the axon-cap (delineated by dotted line) and on ventrally extending small dendrites (small arrows). $C$ and $D$, labeling with 

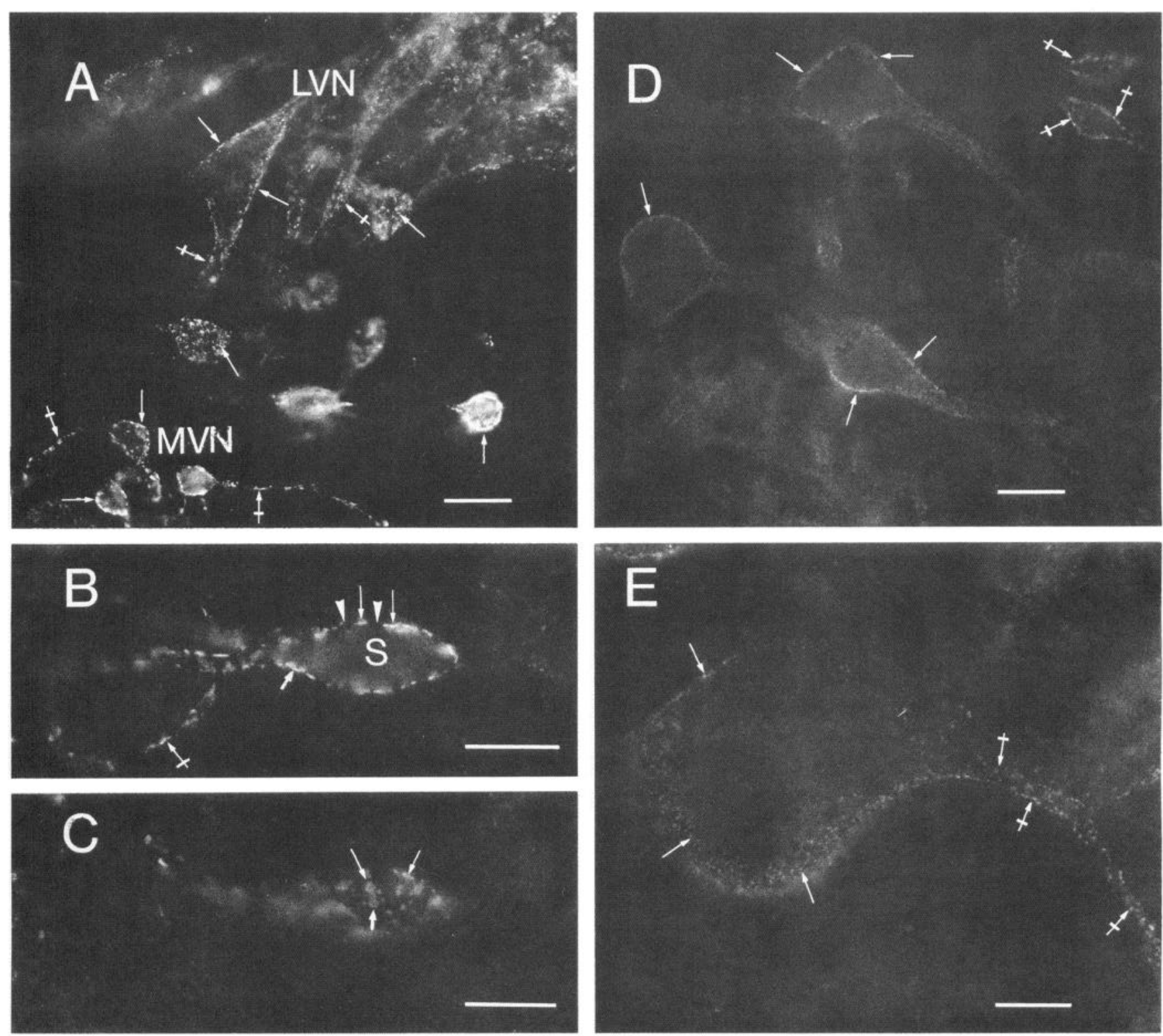

Figure 2. Presence of glycine receptors on vestibular and reticular neurons evidenced with mAb GlyR7a. $A$, Discontinuous labeling of the somata (arrows) and dendrites (crossed arrows) of large neurons belonging to the lateral vestibular nucleus and on smaller cells of the medial vestibular nucleus. $B$ and $C$, Higher-power views showing that the staining is on the surface of, in this case, a small vestibular neuron. $B$, Fluorescent spots (arrows) surrounding the soma and a dendrite (crossed arrow) with free regions between them (arrowheads). C, Same cell as in B, at a different focal plane, with other irregular fluorescent patches (arrows) on its surface. $D$, Staining of large (arrows) and small (crossed arrows) neurons at the level of the reticular nucleus, in the vicinity of the ventral dendrite of the M-cell. $E$, Large reticular neuron with immunofluorescent labeling on its somatic (arrows) and dendritic (crossed arrows) surfaces. Abbreviations: $L V n$, lateral vestibular nucleus; $M V n$, medial vestibular nucleus; $S$. soma. Scale bars: $A$ and $D, 5 \mu \mathrm{m} ; B, C$, and $E, 3 \mu \mathrm{m}$.

level, are due to the interposition between SVBs and such nonglycinergic terminals.

On the middle part of the ventral dendrite, synapses of the flat type (Fig. 6A), analogous to those defined above, were frequently encountered. At more distal portions of the same process, the other type of synaptic contact, already observed at the somatic level, was also present: the stained postsynaptic element was engulfed in the presynaptic membrane of the SVB (Fig. $6 B-$ $D$ ). Generally, these peculiar synapses were most apparent on transverse sections: The labeled postsynaptic membrane was then completely surrounded by the presynaptic element (Fig. 6 , $B$ and $C, \mathrm{SVB}_{2}$ ). One junction of this type was at most observed

GlyR5a of the distal $(C)$ and middle $(D)$ parts of the ventral dendrite. $E$ and $F$, Immunofluorescent patches on the extremity of the lateral dendrite and on some adjacent vestibular neurons. Fluorescent spots (arrows) are separated by large unstained zones (crossed arrow). Abbreviations: $A C$, axon-cap; $M C s$, Mauthner cell soma; $L D$ and $V D$, lateral and ventral dendrites, respectively; Ret $N$ and $V n$, reticular and vestibular nuclei. Scale bars: $A-C$ and $E, 5 \mu \mathrm{m} ; D$ and $F, 3 \mu \mathrm{m}$. 

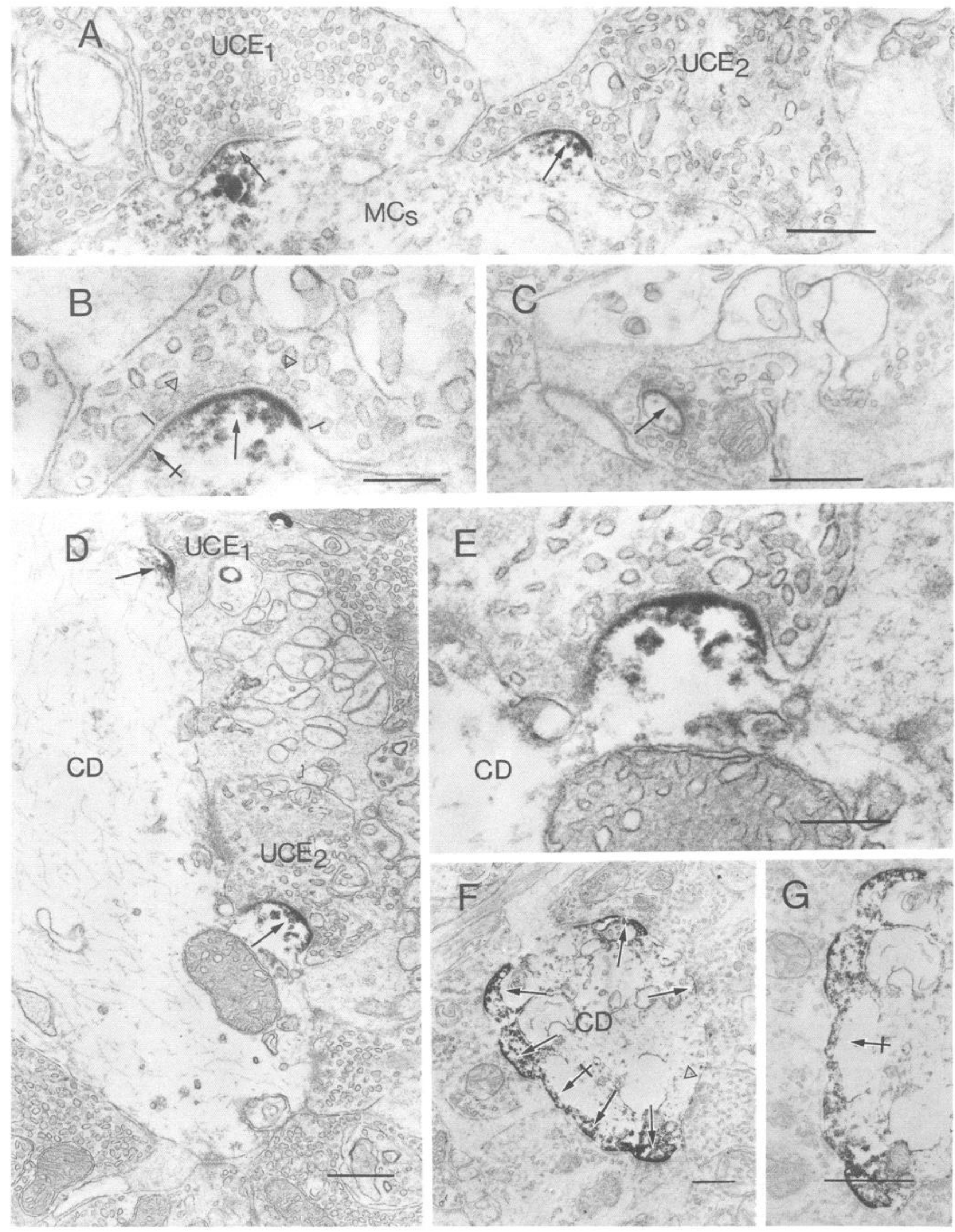

Figure 3. Ultrastructural localization of glycine receptors identified, within the M-cell axon-cap, with the monoclonal antibody GlyR7a. A, Labeling (arrows) at the intracellular side of postsynaptic membranes facing the active zones of 2 unmyelinated club endings $\left(U C E_{l}\right.$ and $\left.U C E_{2}\right)$ impinging on the M-cell soma. $B$, Higher magnification of one of these synapses $\left(\mathrm{UCE}_{2}\right)$ in front of immunoenzymatic product (arrow) is mostly concentrated 
in each bouton, and its frequency of occurrence represented $12 \%$ of the total number of labeled SVBs $(n=170)$. On a longitudinal plane of section, this "invaginated" synapse appears to be connected to the M-cell by a stalk that can be as long as $880 \mathrm{~nm}$ (Fig. 6D). The diameter of the neck is only slightly smaller than that of the tip of the appendage, and when it can be obscrved in its totality, the presynaptic active zone is present not only at the head but also on the shaft of the appendage, as schematized in Figure $6 E$.

\section{Length of the synaptic contacts}

Estimation of the extent of the labeling was difficult to assess because of the fuzziness of the electron-dense reaction product even in its most conspicuous, darkest region, which was directly associated with the plasma membrane of the M-cell. Despite the uncertainties resulting from this situation, the borders of this compact zone were used as landmarks in order to compare, as illustrated in Figure $4 B$, the length of the postsynaptic receptor matrix with that of the presynaptic dense projections.

The size of the release sites, determined by the extension of the presynaptic dense projections, varied in different areas of the cell. Estimated on random transverse sections, its mean diameter was $650 \mathrm{~nm}(\mathrm{SD}=360 \mathrm{~nm}, n=67)$ at the middle of the main dendrites, $310 \mathrm{~nm}(\mathrm{SD}=165 \mathrm{~nm}, n=80)$ on the soma, and $250 \mathrm{~nm}(\mathrm{SD}=115 \mathrm{~nm}, n=44)$ in the axon-cap. The extent of staining on the postsynaptic membrane varied in parallel, with a mean of $930 \mathrm{~nm}(\mathrm{SD}=470 \mathrm{~nm}, n=67), 460$ $\mathrm{nm}(\mathrm{SD}=190 \mathrm{~nm}, n=80)$, and $330 \mathrm{~nm}(\mathrm{SD}=120 \mathrm{~nm}, n=$ 44) for the main dendrites, the soma, and the axon-cap, respectively. Taken 2 by 2 , these means were significantly different $(p<0.03$, Student $t$ test). Thus, on the average, postsynaptic labeling overextended, on each side, the limit of the presynaptic active zone (about $85 \mathrm{~nm}$ ).

\section{Fixation effects on vesicular shape}

The morphology of the synaptic vesicles varied as a function of the fixatives used for this study. The vesicles contained in the terminals apposed to labeled postsynaptic membrane were more elongated with classical bialdehyde fixative (Fig. $7 A$ ) than when the modified basic formaldehyde at $\mathrm{pH} 10.4$ was used (Fig. $7 B$ ). We have quantified this notion using morphological parameters similar to those described by Nakajima (1974).

Two terms were taken into account: $D$ and $d$, the maximum and minimum diameters, respectively. Then, the vesicular shape could be characterized by 3 relationships: (1) the clongation coefficient, which is the ratio $D / d$ (the closer this is to 1 , the rounder are the vesicles); (2) the mean diameter, which, assuming an elliptical profile, is equal to $\sqrt{D d}$; and (3) the vesicular surface, which can be calculated using the formula $\pi D d / 4$. The identification of the terminals, on which the measurements were made, was based upon the fact that they were apposed to immunoreactive Mauthner plasmalemma, as well as their location and ultrastructural characteristics. Thus, values for SVBs and
UCEs are given in Table 1, which shows that the elongation coefficient was decreased when the modified fixative was used, reflecting the rounder appearance of the vesicles. Also, the mean diameter and area were increased with fixation at $\mathrm{pH} 10.4$. These alterations are further illustrated in Figure 8 . When the vesicles bclonging to UCEs and SVBs were grouped together (Fig. $8 \mathrm{~A}$ ), the mean diameter was notably increased by the modified solution ( $p<0.001$, Student $t$ test). Furthermore, the distribution histogram of the mean elongation coefficient of the vesicle population in each bouton taken separately was shifted to the left, indicating that the vesicles were approaching a spherical shape. Taking the data from identical vesicles of both types of endings together, the distribution of their elongation coefficient showed a larger dispersion $(m=2.06 \pm 1.25, n=433)$ in the case of the standard fixative (Fig. $8 C_{I}$ ), suggesting that some vesicles were elongated while others were rounded, with a resulting pleiomorphic population; with the modified fixative (Fig. $8 C_{2}$ ), the population mean was closer to unity $(m=1.59 \pm 0.64, n$ $=669$ ), indicating that the overall shape of the vesicles was then more spherical.

\section{Discussion}

Our observations deal primarily with the adult M-cells and in part with the adjacent vestibular and reticular nuclei. This was a logical material to study since this neuron is inhibited by glycine (Diamond and Roper, 1973; Diamond et al., 1973; Faber and Korn, 1982), an effect of that is blocked by strychnine (Furukawa et al., 1964; Diamond et al., 1973). The exact localization of glycinergic receptors on this neuron and their relationship with release sites were therefore determined at the level of inhibitory interneurons identified morphologically in previous work (Triller and Korn, 1981, 1982).

\section{Distribution and characterization of labeled synapses}

Both antibodies gave identical results: staining at the intracellular side of the postsynaptic membrane. This pattern is similar to that observed in the spinal cord and cerebellum of the rat (Triller et al., 1985, 1987b).

Light microscopic data indicated a discontinuous distribution of the labeling over the entire surface of the M-cell. The number of stained patches and the intensity of the immunofluorescence were higher at the distal part of the lateral dendrite than on the soma, suggesting that the former has a higher proportion of glycinergic boutons. Another possibility is that some boutons locatcd on the soma face a glycinergic matrix, which is either too small or whose density of receptor sites is too low to be detected with present immunocytochemical methods. This hypothesis cannot be ruled out since electron microscopic observations show that many postsynaptic differentiations labeled with the mAbs are larger, on average, on the dendrites $(930 \pm$ $470 \mathrm{~nm}, n=67)$ than on the soma $(460 \mathrm{~nm} \pm 190 \mathrm{~nm}, n=$ 80 ).

Terminals apposed to glycine receptors were identified using

in front of the active zone, the limits of which are indicated by bars. Note that staining is also present at adjacent regions of the membrane (crossed arrow). Also, note the pleiomorphic shape of the presynaptic vesicles, 2 of which were caught during exocytosis (arrow heads). $C$, Other aspect of a labeled somatic synapse, which, in this case, exhibits a spinelike, engulfed shape (arrow: also see text). $D-G$, Immunolabeling of M-cell processes. $D$, Longitudinal section of a cap dendrite with 2 labeled synapses (arrows) established by 2 unmyelinated club endings $\left(U C E_{l}\right.$ and $U C E_{2}$ ). $E$, Higher magnification of the region labeled $\mathrm{UCE}_{2}$ in $D . F$. Transversal section of another cap-dendrite, bearing several distinct synaptic contacts, and labeled postsynaptic membrane (arrows). They are separated from each other by unstained areas of membrane (open arrowhead), although continuous areas of stained plasmalemma (crossed arrow) can be occasionally seen. $G$, Higher magnification of extrasynaptic membrane indicated in $F$ by a crossed arrow: note the continuity of the labeling between the stained synaptic complexes. Abbreviations: $C D$, cap-dendrites; $M C S$, cell soma; $U C E_{1}$ and $U C E_{2}$, unmyelinated club endings 1 and 2, respectively. Scale bars: $A, C, D, F$ and $G, 400 \mathrm{~nm} ; B$ and $E, 200 \mathrm{~mm}$. 

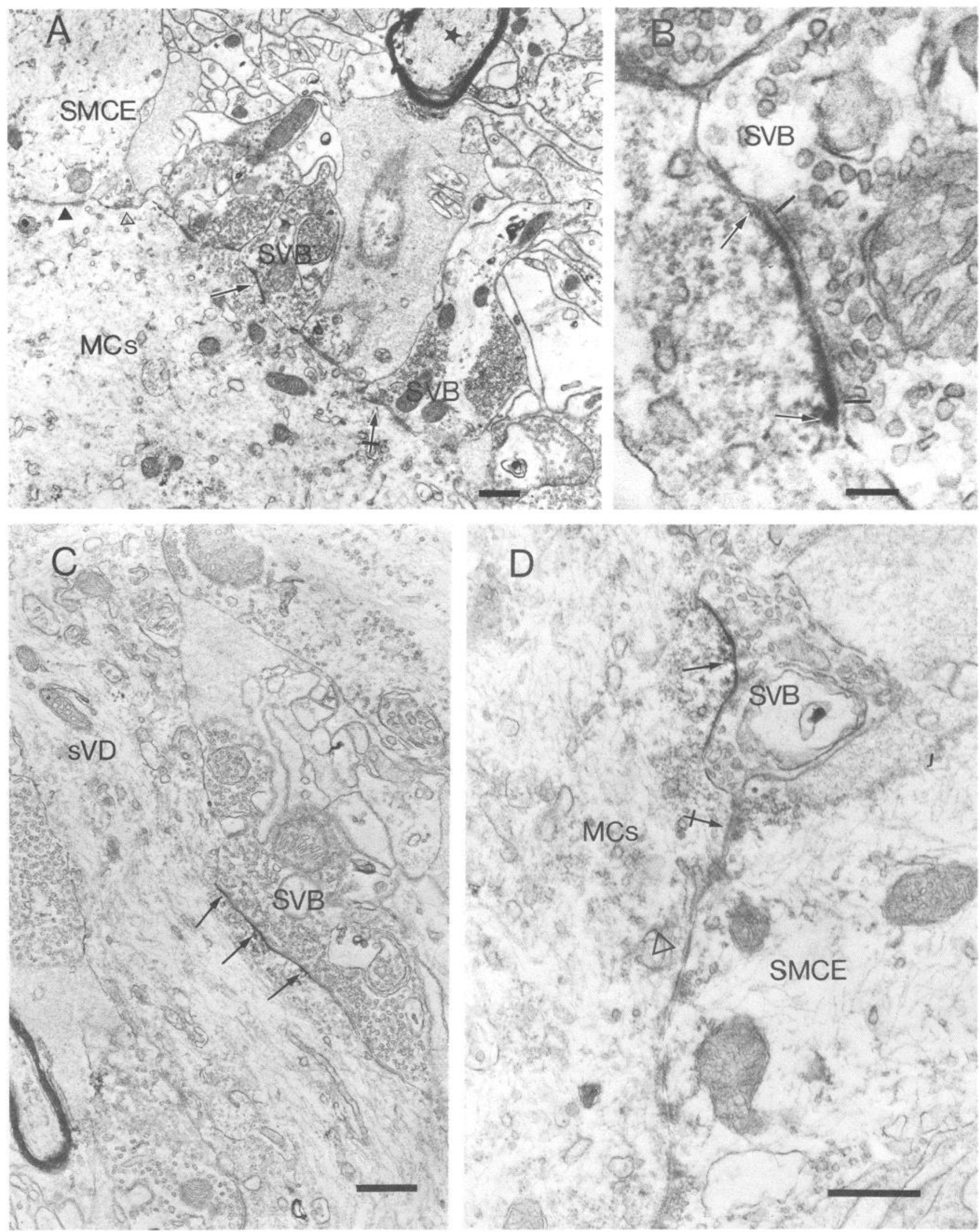

Figure 4. Recognition sites for mAb GlyR7a on postsynaptic differentiations of SVBs contacting the M-cell soma outside the axon-cap. $A$ and $B$, Positive immunoreaction on the plasma membrane. $A$, Immunoreactivity (arrow) at the cytoplasmic side of the membrane facing the active zone of a SVB at some distance from a myelinated fiber (star). Unlabeled postsynaptic differentiations of another SVB (crossed arrow) and of a small myelinated club ending (arrowhead), which also established a gap junction (dark arrowhead) with the M-cell, are present within the plane of section. 

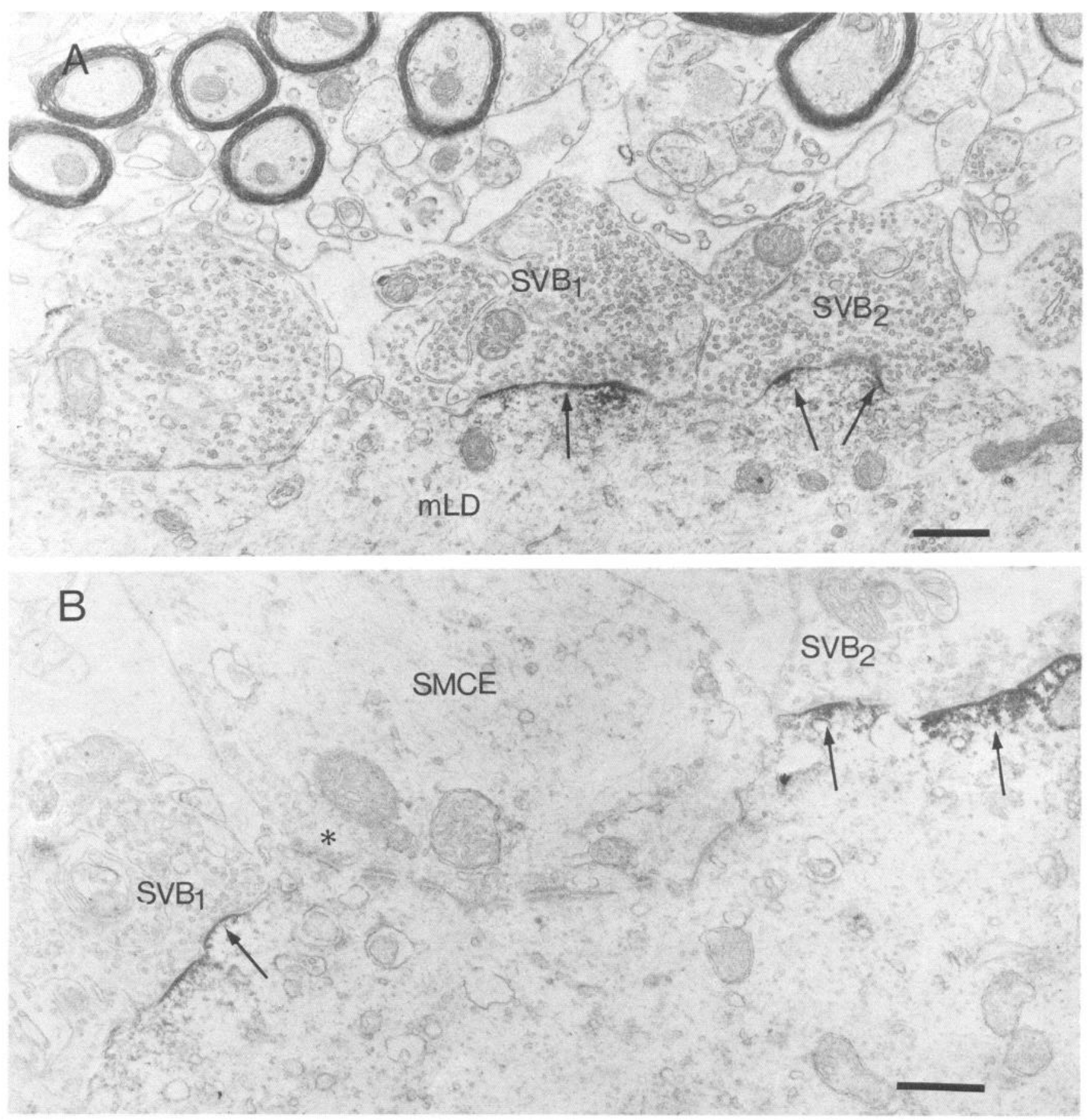

Figure 5. Presence of glycine receptors on the middle part of the M-cell lateral dendrite demonstrated using the monoclonal antibody GlyR 7a. A and $B$, Electron micrographs, both showing 2 small vesicle boutons impinging on the dendritic membrane and apposed to stained postsynaptic differentiations (arrows). In $B$, note the small myelinated club ending bearing at least one active zone (asterisk) facing a nonreactive plasmalemma. Abbreviations: $m L D$, middle part of the lateral dendrite; $S M C E$, small myelinated club ending; $S V B$, and $S V B_{2}$, small vesicle boutons 1 and 2 , respectively. Scale bars, $500 \mathrm{~nm}(A$ and $B)$.

$B$, Higher magnification of the synapse marked by an arrow in $A$. The dense immunoprecipitate (arrows) extends past the limits of the presynaptic active zone (vertical bars). $C$, Long labeled postsynaptic differentiation (arrows) apposed to a small vesicle bouton in contact with a small ventral dendrite. $D$, Labeled active region of a SVB (arrow) located in close proximity to that of an unlabeled small myelinated club ending (crossed arrow); the latter contains round vesicles and is linked by a gap junction (arrowhead) with the M-cell. Abbreviations: MCS, M-cell soma; $S M C E$, small myelinated club ending; $S V B$, small vesicle bouton; $S V D$, small ventral dendrite. Scale bars: $A$, $C$, and $D, 500 \mathrm{~mm} ; B, 100 \mathrm{~nm}$. 

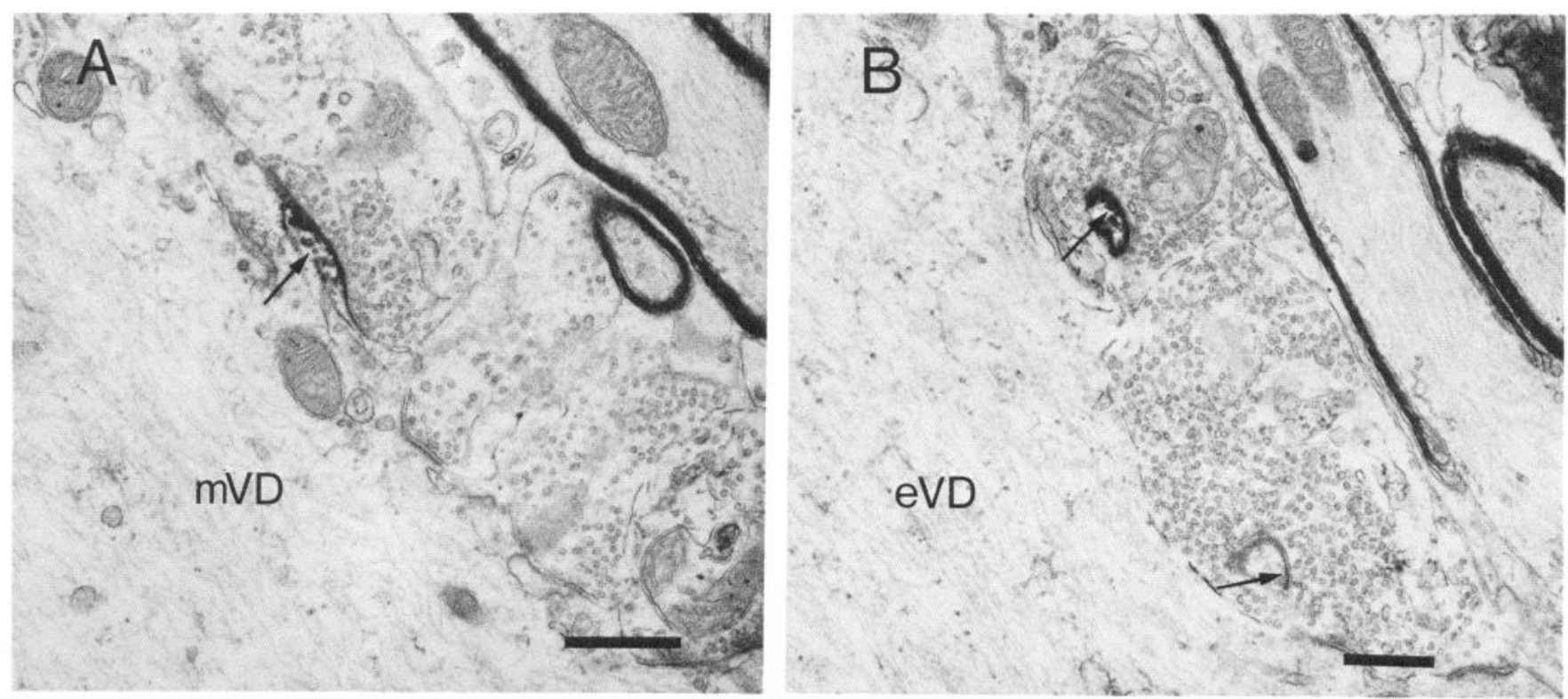

eVD

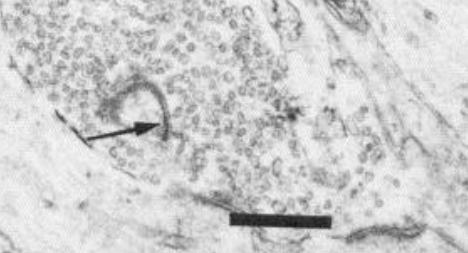

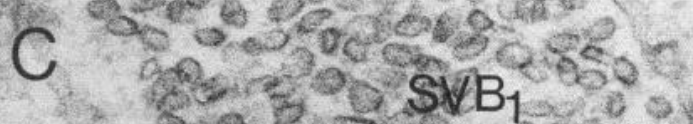

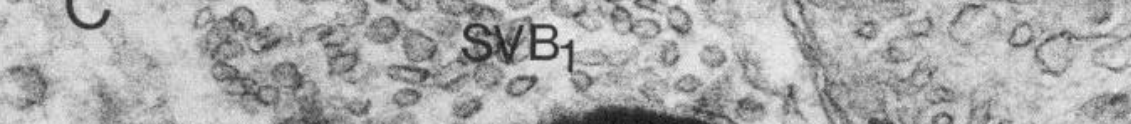

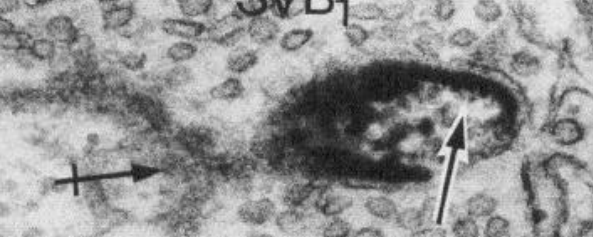

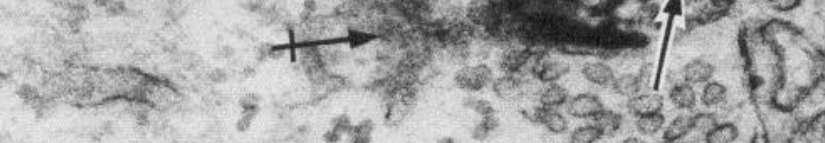

SVB2

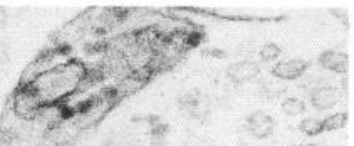

$$
x^{2}=
$$

$x^{2+4}$

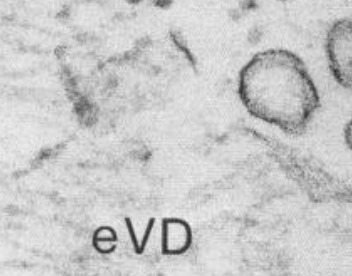

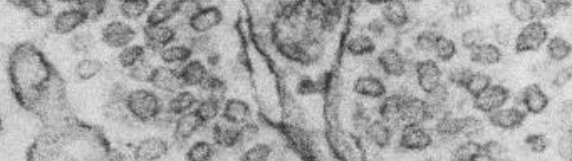
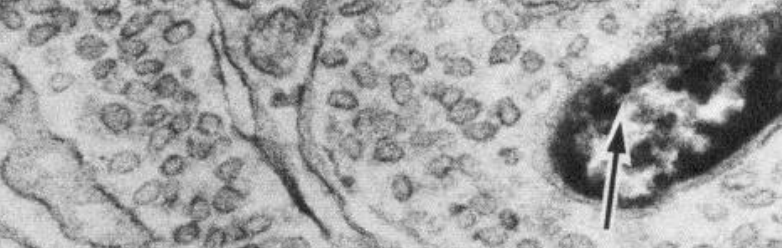

eVD

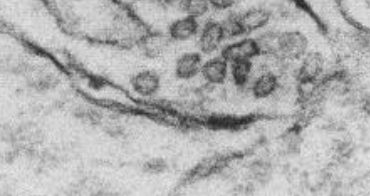
as a d o

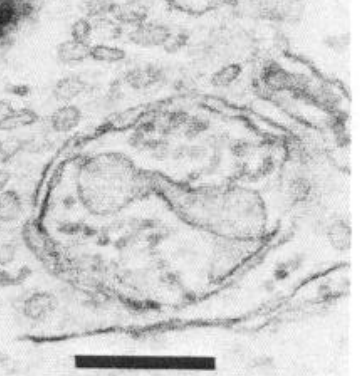

\section{D}

D.<smiles>[LiH]</smiles><smiles>[14CH3]</smiles>

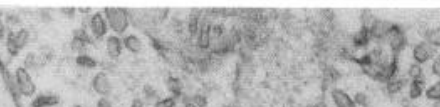

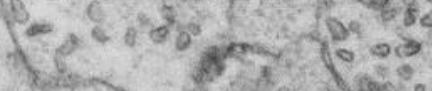

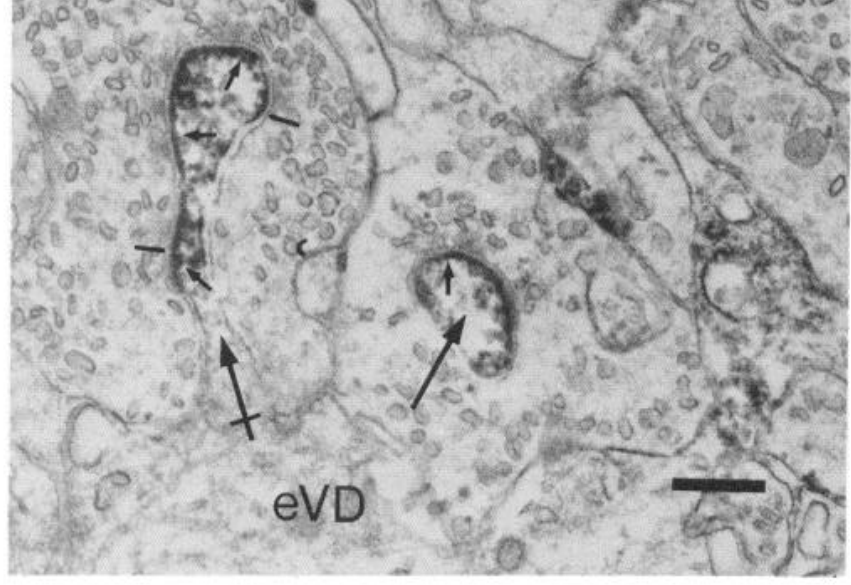

$E$

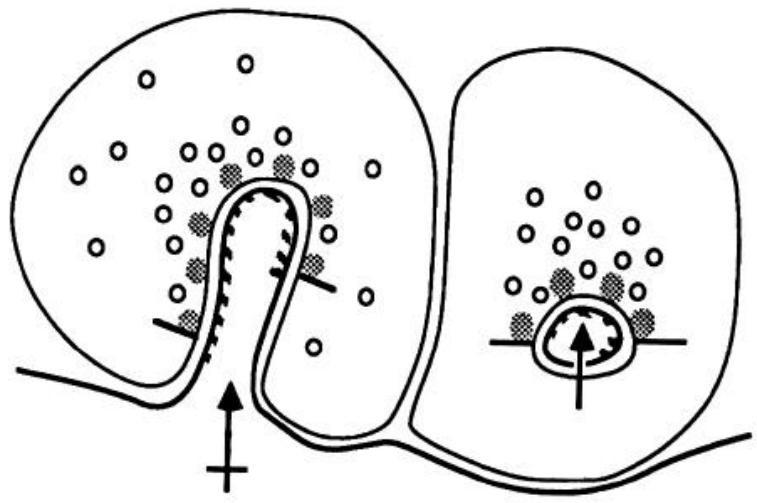

M-CELL eVD 

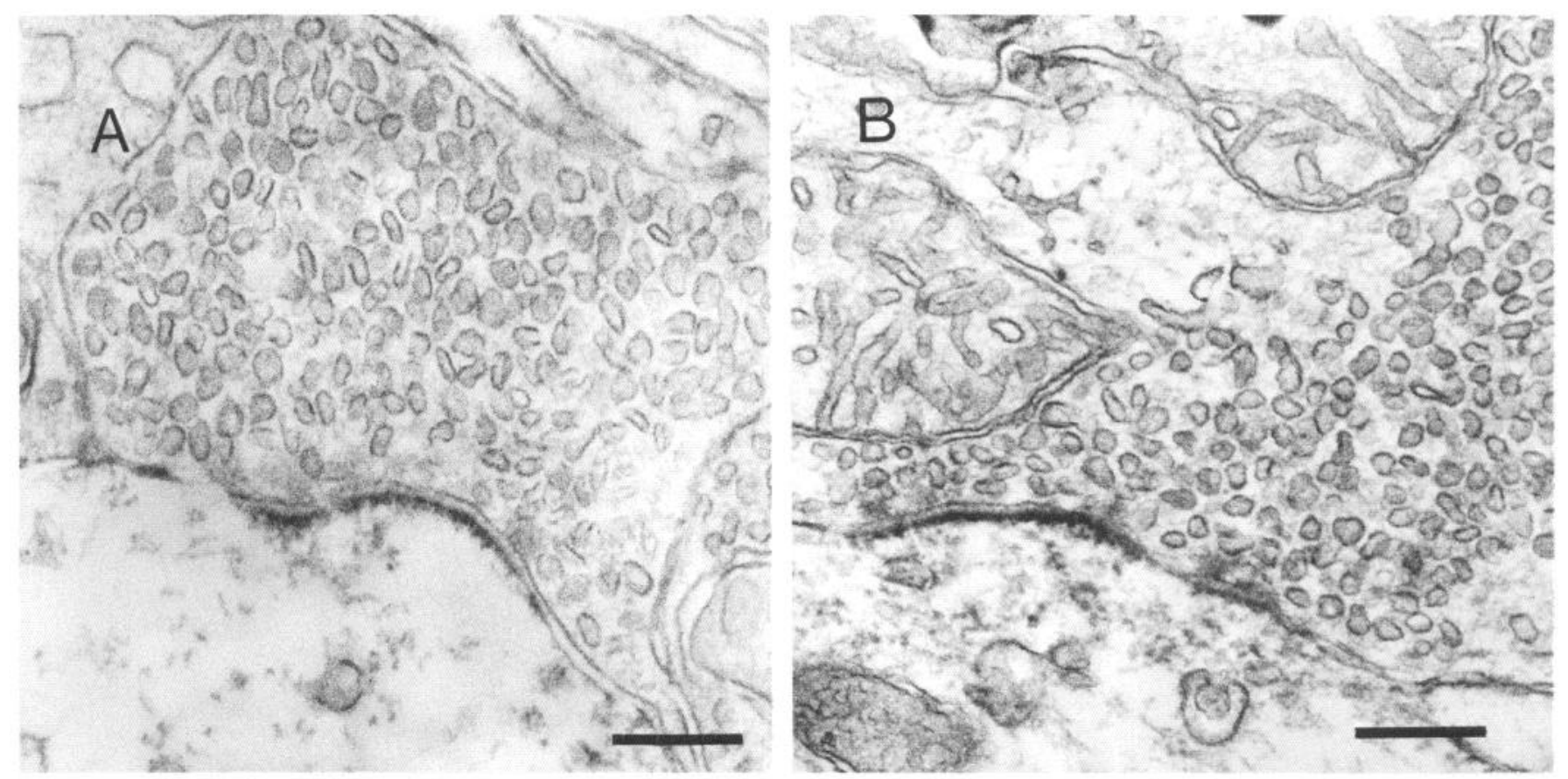

Figure 7. Effect of the fixative's composition on the shape of the presynaptic vesicles contained in terminals apposed to glycine receptors. A, Transverse section of a SVB exhibiting pleiomorphic vesicles after classical fixation with $4 \%$ paraformaldehyde and $0.1 \%$ glutaraldehyde (pH 7.4 ). $B$, Electron micrograph of another bouton obtained from a material fixed using a method allowing optimum penetration of the antibodies; the same procedure as in $A$ was followed by a perfusion of a solution of $4 \%$ paraformaldehyde in sodium bicarbonate (pH 10.4 ) and subsequent treatment with alcohol before osmification (see Materials and Methods for details). Note the rounder aspect of synaptic vesicles in this case. Scale bars, $200 \mathrm{~nm}(A$ and $B)$.

classical morphological criteria (Nakajima, 1974), according to which one group of endings located in the peripheral part of the axon-cap can be identified as UCEs and another group, outside this region, can be recognized as SVBs. The origin and the function of some of these endings is well defined. They belong to 2 categories of interneurons, those constituting the final component of the recurrent collateral network (Korn et al., 1978; Triller and Korn, 1982) and those of the commissural vestibulovestibular pathway (Zottoli and Faber, 1980; Triller and Korn, 1981). Both types of cells mediate a $\mathrm{Cl}^{-}$-dependent inhibition of the M-cell (Faber and Korn, 1982). It has been shown that each of these neurons can give rise to both UCEs and SVBs (Triller and Korn, 1981). The cells terminate in a well-organized manner (Triller and Korn, 1986): their terminal boutons are concentrated within the axon-cap, on the soma outside this region, and on the initial portions of the main dendrites, their number decreasing progressively along these processes. In confirmation, these regions were found to be stained by the antibodies, in front of UCEs and SVBs. On the other hand, the cells of origin of the SVBs, which are located on more distal parts of the dendrites, remain unknown.

In this study, the control of labeling specificity consisted in the lack of staining when the first antibody was omitted. More direct evidence, such as preincubation of these mAbs with the goldfish $93 \mathrm{kDa}$ glycine receptor subunit, was not possible since this peptide has not yet been purified from goldfish material. However, labeling was present in front of terminals, namely UCEs, which have been shown, electrophysiologically, to be glycinergic (Faber et al., 1983). In addition, no labeling of postsynaptic membranes in front of excitatory afferents of the M-cell, i.e., of small and large myelinated club endings or large vesicle boutons, was observed.

Immunofluorescence staining was observed in other regions of the brain stem, including the vestibular and reticular nuclei. In these structures, the labeling had the same patchy appearance as on the M-cell. The origin of the afferents apposed to the immunostaining was not identified, except in the case of the commissural vestibulovestibular fibers, which inhibit the 2 M-cells and which send collaterals to the vestibular and reticular neurons (Triller and Korn, 1978, 1981). These projections are more likely to be glycinergic since their effect on the M-cell is blocked by strychnine (Faber et al., 1983).

\section{Morphological structure and inhibitory function}

In our material, terminals facing postsynaptic glycinergic matrices were SVBs and UCEs, which establish asymmetrical Gray

Figure 6. Evidence obtained with mAb GlyR7a that glycine receptors are present on the ventral dendrite and spinelike structures at the level of the M-cell. $A$, Immunostained postsynaptic membrane (arrow) facing a small vesicle bouton at the middle part of the process. $B$ and $C$, Labeled spinelike synaptic contacts (arrows) at the extremity of the ventral dendrite. $B$, Two examples of labeled postsynaptic membrane (arrows) engulfed by the presynaptic terminal. $C$, Bird's-eye view of 2 stained circular synapses (arrows) belonging to adjacent terminals. Note that the neck of the appendage (crossed arrow) is visible in the case of the contact with SVB S. $^{2}$, Longitudinal (crossed arrow) and transverse (arrow) sections of invaginated synaptic contacts; the former is characterized by the size of its presynaptic active zone (between bars), which extends over a large proportion of the appendage. $E$, Diagrammatic representation of the synaptic contacts illustrated in $D$, emphasizing (1) that the presynaptic dense projections occupy a large portion of the invaginated membrane and (2) that the postsynaptic labeling associated with the active zone (bold line with hash marks) is also found on the shaft of the appendage. Abbreviations: $e V D$ and $m V D$, extremity and middle part of the ventral dendrite, respectively; $S V B_{1}$ and $S V B_{2}$, small vesicle boutons 1 and 2 . Scale bars: $A$ and $B, 500 \mathrm{~nm} ; C$ and $D, 200 \mathrm{~nm}$. 

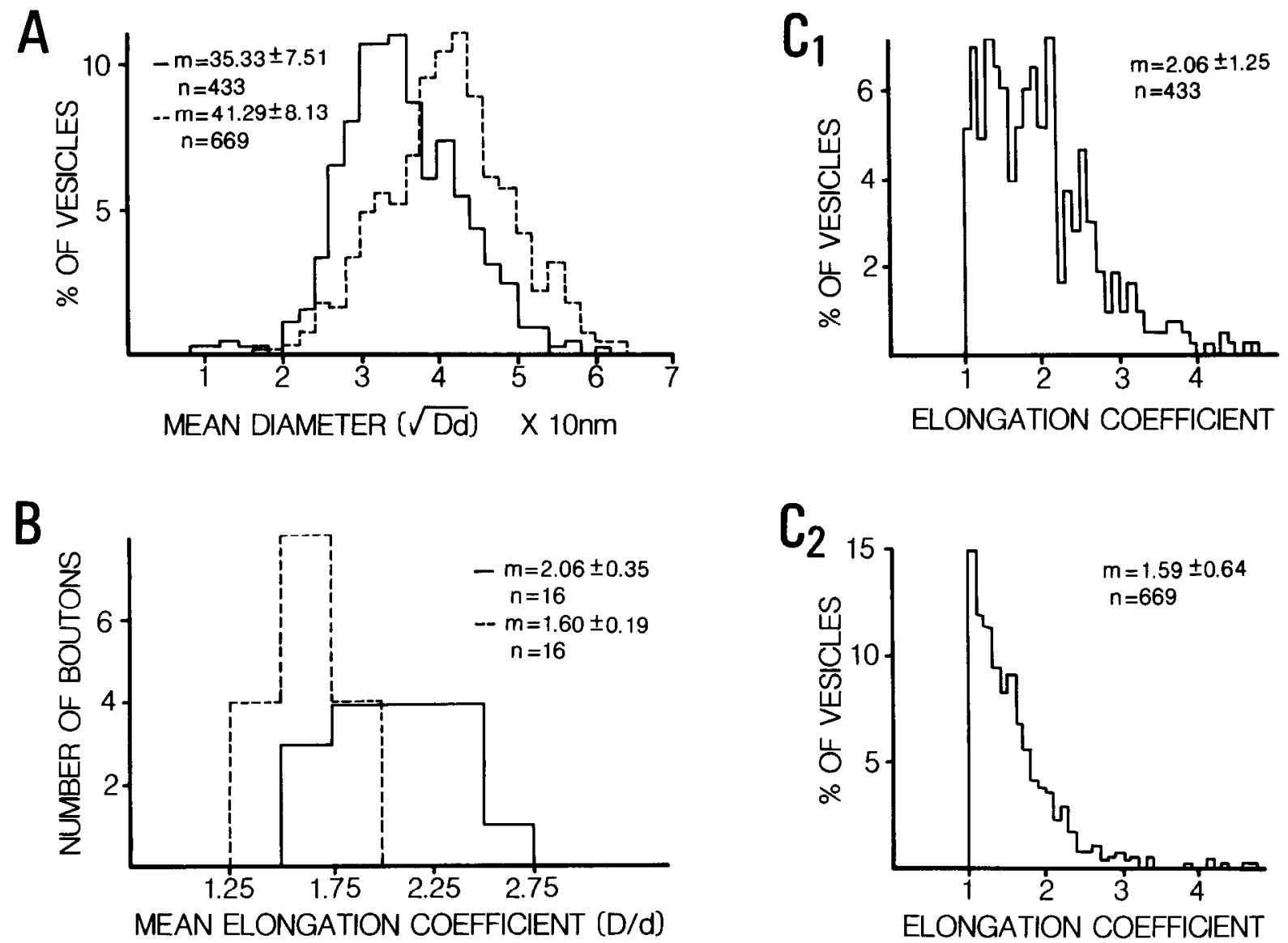

Figure 8. Morphometric data relative to the effect of fixatives on the shape of synaptic vesicles. All data are from terminals apposed to immunolabeled postsynaptic densities. $A$ and $B$, Frequency histograms of the mean diameter $(A)$ and elongation coefficient of synaptic vesicles $(B)$ in presence of the modified (dotted line) and standard aldehydic (solid line) fixatives. Note that the vesicles are enlarged and rounder after fixation with the former. The significance of these modifications was confirmed by Student's $t$ test, which rejected $(p<0.05)$ the equality of means. $C_{1}$ and $C_{2}$, Frequency histograms of the elongation coefficient (abscissa) of vesicles in presence of the standard $\left(C_{1}\right)$ and modified $\left(C_{2}\right)$ fixatives. Note the larger mean, and the scatter of data, in the first histogram. Means, SDs, and size of samples are indicated.

type II synapses (Gray, 1959) with a content of pleiomorphic vesicles after classical aldehyde fixation. Morphometric analysis yielded results slightly different from those observed by Nakajima (1974), who gave slightly larger values. This discrepancy can be explained by the composition of the fixative, which was $4 \%$ PFA and $0.1 \%$ GA in our experiments, as opposed to $1 \%$ of each aldehyde in the earlier study. In addition, when we used a more alkaline but similar bialdehydic fixative, the vesicles were slightly more spherical. This observation reinforces the notion that the geometrical aspect of vesicles depends primarily upon the chemical composition of the fixative.

The synaptic contacts established on the M-cell by boutons apposed to glycine receptors display various forms, from the classical flat shape to invaginated synapses. These last junctions are described here for the first time in the case of the M-cell, and in addition, no identified inhibitory contact has been reported to exhibit this type of structure in any system. They cannot be called spines per se since their synaptic complex extends over all the surface of the appendage, including its shaft. These labeled synapses were more frequently seen on the distal part of the ventral dendritc, where they represented up to $12 \%$ (as estimated from random sections) of the total number of labeled SVBs, than on the other portions of the M-cell, where they averaged less than $3 \%$. Comparable types of "indented synapses," at the level of which the postsynaptic membrane extensively invaginates in the presynaptic element, have been found in Aplysia californica (Bailey and Thomson, 1979; Bailey et al., 1979), where their involvement in learning has been suggested. Also, they share common features with the complex spine-synapses established by excitatory mossy fibers on the apical dendrites of pyramidal cells of the rabbit hippocampus (Hamlyn, 1962). One can reasonably expect from their morphology that inhibitory synapses operate in a different manner than the classical spines associated with excitatory junctions. In the latter, the high access resistance of the spine, due to its narrow neck, converts the junction into a constant-current generator and isolates the rest of the dendrite from conductance changes in this localized region (Llinás and Hillman, 1969). Such an effect would, in fact, minimize inhibition by reducing the shunt, which is more significant than the voltage drop. An alternative role may be linked to the larger surface area of the contact zone, which would limit transmitter diffusion away from the receptor matrix and thereby increase inhibitory effects on adjacent excitatory inputs.

\section{Evaluation of the extension of the glycine receptor matrix}

A model of inhibitory responses evoked in M-cell by individual release sites predicted (Faber et al., 1985) that the area of postsynaptic membrane containing the glycine receptors should ex- 
tend beyond the limit of the postsynaptic density facing the active zone. Calculations took into account parameters such as (1) the quantal conductance change and the conductance of single glycine activated chloride channel (see also Korn et al., 1987) and (2) structural variables such as the size of the synaptic complex and the number of receptors that could be reasonably accommodated by this region.

Morphological data reported here indicated that the immunolabeling slightly overlapped the limits of the synaptic complex, but less than predicted on the basis of indirect calculations. The immunostaining procedure we used to visualize the receptors at the electron microscopic level may not be the most appropriate for estimating the exact extension of the labeled postsynaptic glycine receptor matrix. With our preembedding staining procedure, at least 2 artifacts with opposite consequences may influence the size of the labeled area. The first is related to the variability of penetration of the antibodies and of the immunoreactive substances in the tissue. This can cause a decrease of concentration of these molecules and thus a low sensitivity to receptor detection. To minimize this effect, we have restricted our observations to surface sections. The second, which predominates in our preparation, leads to an overestimation of the size of the actual immunolabeled postsynaptic membranes: The diaminobenzidine oxidized by the peroxidase does precipitate and adsorbs on nonsoluble elements such as the cytoskeleton or adjacent perisynaptic membranes. Along this line, one should note that the results reported here are quite comparable to those obtained with the same technique in the rat spinal cord. The glycinergic synapses were also stained in the latter, with the preembedding colloidal gold procedure, the overextension of the receptor matrix was generally no more than $60 \mathrm{~nm}$ (Triller et al., 1985), but with this procedure the detection sensitivity was decreased due to barriers to gold particle diffusion. In any case, for synapses located in the axon-cap an overextension of $85 \mathrm{~nm}$ (see Results) is less than predicted by the model (Faber ct al., 1985). Various possibilities may account for this discrepancy. First, the concentration of glycinergic receptors present at the periphery of the synaptic complex itself may be too low to be detected by our immunocytochemical procedure (see also Brown and Farquhar, 1984). A second possibility may involve other receptors, such as glycinergic ones, (1) not recognized by the mAbs that we have used, i.e., not associated with the 93 $\mathrm{kDa}$ subunit, and composed for instance by the two remaining identified subunits 48 and $58 \mathrm{kDa}$ (Pfeiffer et al., 1984), or (2) not strychnine-sensitive (Ryall et al, 1972). Receptors for another transmitter, such as GABA, may also be involved; however, despite evidence that GABAergic terminals can be apposed to glycine receptors in the rat spinal cord (Triller et al., 1987b), this hypothesis is not the most likely, because one does not consistently obtain such results in the M-cell system (Triller et al., 1987a), where, in addition, unitary responses evoked after stimulation of single inhibitory interneurons are suppressed by strychnine (Faber et al., 1983).

\section{Functional implications}

It is remarkable that glycine receptors are widely distributed on the whole surface of the M-cell, where various types of input (and corresponding junctions) are well segregated; hence, it is probable that they are involved in different functions, despite the fact that their activation is monotonously mediated through $\mathrm{Cl}^{-}$conductance increases. Their distribution, which includes both soma and dendritic processes, is similar to that observed
Table 1. Comparison of the shape and size of synaptic vesicles in UCEs and SVBs treated with standard and modified fixatives (pH 10.4)

\begin{tabular}{llll} 
Treatment & $\begin{array}{l}\text { Elongation } \\
\text { coefficient, } \\
D / d\end{array}$ & $\begin{array}{l}\text { Diameter, } \sqrt{D d} \\
(\mathrm{~nm})\end{array}$ & $\begin{array}{l}\mathrm{Area}, \pi D d / 4 \\
\left(\mathrm{~nm}^{2} \times 10^{2}\right)\end{array}$ \\
\hline UCEs & & & \\
$\quad$ Standard & $2.19 \pm 1.80$ & $32.54 \pm 6.42$ & $8.63 \pm 3.43$ \\
$(5)$ & $n=142$ & $n=142$ & $n=142$ \\
pH 10.4 & $1.64 \pm 0.66$ & $43.68 \pm 7.82$ & $15.46 \pm 5.38$ \\
$(8)$ & $n=401$ & $n=401$ & $n=401$ \\
SVBs & & & \\
Standard & $2.00 \pm 0.87$ & $36.69 \pm 7.64$ & $11.02 \pm 4.45$ \\
$(11)$ & $n=291$ & $n=291$ & $n=291$ \\
pH 10.4 & $1.50 \pm 0.59$ & $37.71 \pm 7.23$ & $11.57 \pm 4.30$ \\
$(8)$ & $n=267$ & $n=267$ & $n=267$ \\
\hline
\end{tabular}

Numbers of measured boutons are indicated in parentheses; $n$ is the number of vesicles examined; $D$ and $d$ stand for the large and the small diameter of the vesicles, respectively. The results are expressed as means \pm SD.

in the reticular and vestibular nuclei (see Fig. 2) and in the ventral horn of the rat spinal cord, including motoneurons (Triller et al., 1985). However, this situation is not the rule. For example, it contrasts with that in the rat cerebellum, where Purkinje cells express glycine receptor-like immunoreactivity along their dendrites but not on their somatic membrane (Triller et al., 1987b). Such might be the case for receptors to glutamate at both the M-cell and the Purkinje cells; although specific probes for these receptors do not exist, iontophoretic injections in the former (Diamond and Roper, 1973) and immunocytochemistry for the latter (Somogyi et al., 1986) support regionalization of glutamate receptors on the dendrites. Whether the expression of a given receptor at a given cellular locus is innervation dependent remains to be detcrmined.

The inhibitory role of terminals apposed to glycinergic receptors is well established, at least for the terminals located in or near the axon-cap, since most of them, identified morphologically with intracellular injections (Triller and Korn, 1981, 1982), activate chloride conductances when selectively stimulated (Korn and Faber, 1976; Faber and Korn, 1982) and since this effect is blocked by strychnine (Faber et al., 1983). They are responsible for the somatic inhibition of the cell. Concerning the other endings apposed to similar receptive matrices and located on the middle and distal part of dendrites, one can hypothesize that they mediate the remote dendritic inhibition (Diamond, 1968) that shunts the excitatory responses evoked, for example, after vestibular or lateral line nerve stimulations (Korn and Faber, 1975a).

Given the ubiquity of inhibitory boutons, inhibition is guaranteed to exert an influence on the diverse inputs to the cell. For example, on the distal part of the lateral dendrite, glycine receptors facing SVBs are interposed between primary vestibular afferents, i.e., the large myelinated club endings, where the chemical synapses are predominately located at the periphery of the synaptic contact (Kohno and Noguchi, 1986; Tuttle et al., 1986), and are therefore close to the surrounding SVBs. At the middle of this dendritc, the SVBs are adjacent to large vesicle boutons, which probably originate from the medial longitudinal fasciculus and the eighth nerve (Nakajima, 1974). This last region also receives inputs from the lateral line nerve (Korn and Faber, 1975a), probably ending through small myelinated club 
endings and/or large vesicle boutons. It should be recalled that glycine potentiates responses to $N$-methyl-D-aspartate, an agonist of the glutamate receptors, in cultured mouse neurons (Johnson and Ascher, 1987), and since the lateral dendrite of the M-cell is depolarized by L-glutamate (Diamond and Roper, 1973), it is possible that this last amino acid is released by some afferents to the M-cell. Thus, facilitatory interactions might occur in the M-cell system, provided that glycine present in the extracellular space does not already saturate the allosteric binding sites on the glutamate receptor, even in the absence of evoked inhibition.

Another synaptic interaction may occur on the lateral dendrite. This process is sensitive to iontophoretic applications of GABA, which, as glycine, activates chloride conductances (Diamond and Roper, 1973). It has been proposed that the 2 neurotransmitters have a positive cooperative interaction through their receptors (Werman, 1980). It is important to note here that both amino acids may coexist in the same presynaptic terminals, as suggested for the spinal cord (Triller et al., 1987b) and cerebellum of the rat (Ottersen et al., 1987; Triller et al., 1987b). At the level of the M-cell (Triller et al., 1987a), only few GABAergic terminals, recognized by the presence of the glutamic acid decarboxylase (a synthetic enzyme for GABA), were apposed to glycinergic receptors. However, it has been shown that GABAergic receptors are present over large areas of the M-cell (see Faber and Korn, 1982); they may be involved in the transduction of signals arising from the large fraction of SVBs that are not apposed to a glycinergic matrix.

\section{References}

Alger, B. E., and R. A. Nicoll (1982) Feed-forward dendritic inhibition in rat hippocampal pyramidal cells studied in vitro. J. Physiol. (Lond.) 328: 105-123.

Altschuler, R. A., H. Betz, M. H. Parakkal, K. A. Reeks, and R. J. Wenthold (1986) Indentification of glycinergic synapses in the cochlear nucleus through immunocytochemical localization of the postsynaptic receptor. Brain Res. 369: 316-320.

Aprison, M. H., and E. C. Daly (1978) Biochemical aspects of transmission at inhibitory synapses: The role of glycine. Adv. Neurochem. 3: 203-294

Aprison, M. H., R. P. Shank, and R. A. Davidoff (1969) A comparison of the concentration of glycine, a transmitter suspect, in different areas of the brain and spinal cord in seven different vertebrates. Comp. Biochem. Physiol. 28: 1345-1355.

Bailey, C. H., and E. B. Thompson (1979) Indented synapses in Aplysia. Brain Res. 173: 13-20.

Bailey, C. H., E. B. Thompson, V. F. Castellucci, and E. R. Kandel (1979) Ultrastructure of the synapses of sensory neurons that mediate the gill-withdrawal reflex in aplysia. J. Neurocytol. 8: 415-444.

Bartelmez, G. W. (1915) Mauthner's cell and the nucleus motorius tegmenti. J. Comp. Neurol. 25:87-128.

Berod, A., B. K. Hartman, and J. F. Pujol (1981) Importance of fixation in immunocytochemistry: Use of formaldehyde solutions at variable $\mathrm{pH}$ for the localization of tyrosine hydroxylase. J. Histochem. Cytochem. 29: 844-850.

Brooks, V. B., and V. J. Wilson (1959) Recurrent inhibition in the cat's spinal cord. J. Physiol. (Lond.) 146: 380-391.

Brown, W. J., and M. G. Farquhar (1984) The mannose-6-phosphate receptor for lysosomal enzymes is concentrated in cis Golgi cistcrnac. Cell 36: 295-307.

Cohen, E., and P. Sterling (1986) Accumulation of ${ }^{3} \mathrm{H}$-glycine by cone bipolar cells in the cat retina. J. Comp. Neurol. 250: 1-7.

Diamond, J. (1968) The activation and distribution of GABA and L-glutamate receptors on goldfish Mauthner neurones: An analysis of dendritic remote inhibition. J. Physiol. (Lond.) 194: 669-723.

Diamond, J., and S. Roper (1973) Analysis of Mauthner cell responses to iontophoretically delivered pulses of GABA, glycine and L-glutamate. J. Physiol. (Lond.) 232: 113-128.

Diamond, J., S. Roper, and G. M. Yasargil (1973) The membrane effects, and sensitivity of strychine, of neural inhibition of the Mauthner cell, and its inhibition by glycine and GABA. J. Physiol. (Lond.) 232: 87-111.

Eccles, J. C. (1969) The Inhibitory Pathways of the Central Nervous System, Charles C. Thomas, Springfield, IL.

Eccles, J. C., P. Fatt, and K. Koketsu (1954) Cholinergic and inhibitory synapses in a pathway from motor-axon collaterals to motoneurons. J. Physiol. (Lond.) 126: 524-562.

Faber, D. S., and H. Korn (1973) A neuronal inhibition mediated electrically. Science 179: 577-578.

Faber, D. S., and H. Korn (1982) Transmission at a central inhibitory synapse. I. Magnitude of unitary postsynaptic conductance change and kinetics of channel activation. J. Neurophysiol. 48: 654-678.

Faber, D. S., H. Korn, and A. Triller (1983) Quantal analysis of strychnine action at a presumed glycinergic central synapse. Soc. Neurosci. Abstr. 9: 456

Faber, D. S., P. G. Funch, and H. Korn (1985) Evidence that receptors mediating central synaptic potentials extend beyond the postsynaptic density. Proc. Natl. Acad. Sci. USA 82: 3504-3508.

Frostholm, A., and A. Rotter (1985) Glycine receptor distribution in mouse CNS: Autoradiographic localization of $\left[{ }^{3} \mathrm{H}\right]$ strychnine binding sites. Brain Res. Bull. 15: 473-486.

Furukawa, T., Y. Fukami, and Y. Asada (1964) Effects of strychnine and procaine on collateral inhibition of the Mauthner cell of goldfish. Jpn. J. Physiol. 14: 386-399.

Granit, R., J. O. Kellerth, and T. D. Williams (1964) "Adjacent" and "Remote" postsynaptic inhibition in motoneurones stimulated by muscle stretch. J. Physiol. (Lond.) 174: 453-472.

Gray, E. G. (1959) Axo-somatic and axo-dendritic synapses on the cerebral cortex; an electron microscope study. J. Anat. 93: 420-433.

Hamlyn, L. M. (1962) The fine structure of the mossy fibre endings in the hippocampus of the rabbit. I. Anat. 96: 112-120.

Hökfelt, T., and A. Ljungdahl (1971) Light and electron microscopic autoradiography on spinal cord slices after incubation with labelled glycine. Brain Res. 32: 189-194.

Hsu, S. M., L. Raine, and H. Fanger (1981) Use of avidin-biotinperoxidase complex $(\mathrm{ABC})$ in immunoperoxidase techniques: $\mathrm{A}$ comparison between $A B C$ and unlabelled antibody (PAP) procedures. J. Histochem. Cytochem. 29: 577-580.

Johnson, J. W., and P. Ascher (1987) Glycine potentiates the NMDA response in culture mouse brain neurons. Nature 325: 529-531.

Kohno, K., and N. Noguchi (1986) Large myelinated club endings on the Mauthner cell in the goldfish: A study with thin sectioning and freeze-fracturing. Anat. Embryol. 173: 361-370.

Korn, H., and D. S. Faber (1975a) Inputs from the posterior lateral line nerves upon the goldfish Mauthner cell. I. Properties and synaptic localization of the excitatory component. Brain Res. 96: 342-348.

Korn, H., and D. S. Faber (1975b) An electrically mediated inhibition in goldfish medulla. J. Neurophysiol. 38: 452-471.

Korn, H., and D. S. Faber (1976) Vertebrate central nervous system: Same neurons mediate both electrical and chemical inhibitions. Science 194: 1166-1169.

Korn, H., A. Triller, and D. S. Faber (1978) Structural correlates of recurrent collateral interneurons producing both electrical and chemical inhibitions of the Mauthner cell. Proc. R. Soc. London [Biol.] 202: 533-538.

Korn, H., Y. Burnod, and D. S. Faber (1987) Spontaneous quantal currents in a central neuron match predictions from binomial analysis of evoked responses. Proc. Natl. Acad. Sci. USA 84: 5981-5985.

Larson, M. D. (1969) An analysis of the action of strychnine on the recurrent IPSP and amino acid induced inhibitions in the cat spinal cord. Brain Res. 15: 185-200.

Leenen, P. J., A. M. Jansen, and W. Van Ewijk (1985) Fixation parameters for immunocytochemistry: The effect of glutaraldehyde or paraformaldehyde fixation on the preservation of mononuclear phagocyte differentiation antigens. In Techniques in Immunocytochemistry, Vol. 3, G. R. Bullock and P. Petrusz, eds., pp. 1-24, Academic, London.

Llinás, R., and D. E. Hillman (1969) Physiological and morphological organization of the cerebellar circuits in various vertebrates. In Neurobiology of the Cerebellar Evolution and Development, R. Llinás, ed., pp. 43-73, Chicago AMA-ERF Institute for Biomedical Research

Nakajima, Y. (1974) Fine structure of the synaptic endings on the Mauthner cell of the goldfish. J. Comp. Neurol. 156: 375-402.

Ottersen, O. P., S. Davanger, and J. Storm-Mathisen (1987) Glycinelike immunoreactivity in the cerebellum of the rat and Senegalese 
baboon, Papio papio: A comparison with the distribution of GABAlike immunoreactivity and with $\left[{ }^{3} \mathrm{H}\right]$ glycine and $\left[{ }^{3} \mathrm{H}\right] \mathrm{GABA}$ uptake. Expl. Brain Res. 66: 211-221.

Palacios, J. M., J. K. Wamsley, M. A. Zarbin, and M. J. Kuhar (1981) GABA and glycine receptors in rat brain: Autoradiographic localisation. In Amino Acid Neurotransmitters, F. V. DeFeudis and P. Mandel, eds, pp. 445-451, Raven, New York.

Pfeiffer, F., R. Simler, G. Grenningloh, and H. Betz (1984) Monoclonal antibodies and peptide mapping reveal structural similarities between the subunits of the glycine receptor of the rat spinal cord. Proc. Natl. Acad. Sci. USA 81: 7224-7227.

Pourcho, R. G. (1980) Uptake of $\left[{ }^{3} \mathrm{H}\right]$ glycine and $\left[{ }^{3} \mathrm{H}\right] \mathrm{GABA}$ by amacrine cells in the cat retina. Brain Res. 198: 333-346.

Probst, A., R. Cortes, and J. M. Palacios (1986) The distribution of glycine receptors in the human brain. A light microscopic autoradiographic study using $\left[{ }^{3} \mathrm{H}\right]$ strychnine. Neuroscience $17: 11-35$

Reynolds, E. S. (1963) The use of lead citrate at high $\mathrm{pH}$ as an electron opaque stain in electron microscopy. J. Cell Biol. 17: 208-212.

Ryall, R. W., M. F. Piercey, and C. Polosa (1972) Strychnine-resistant mutual inhibition of Renshaw cells. Brain Res. 41:119-129.

Schmitt, B., P. Knaus, C. M. Becker, and H. Betz (1987) The $\mathrm{Mr}$ 93000 polypeptide of the postsynaptic glycine receptor complex is a peripheral membrane protein. Biochemistry 26: 805-811.

Somogyi, P., K. Halasy, J. Somogyi, J. Storm-Mathisen, and O. P. Ottersen (1986) Quantification of immunogold labelling reveals enrichment of glutamate in mossy and parallel fibre terminals in cat cerebellum. Neuroscience 19: 1045-1050.

Tello, F. (1909) Contribucion al conoscimento del encefalo de los teleosteos. Los nucleos bulbares. Trab. Lab. Invest. Biol. Univ. Madrid 7: 1-29.

Triller, A., and H. Korn (1978) Mise en évidence électrophysiologique et anatomique de neurones vestibulaires inhibiteurs commissuraux chez la tanche (Tinca tinca). C. R. Acad. Sci. (Paris), Sér. D, 286: 8992.

Triller, A., and H. Korn (1981) Morphologically distinct classes of inhibitory synapses arise from the same neurons: Ultrastructural identification from crossed vestibular interneurons intracellularly stained with HRP. J. Comp. Neurol. 203: 131-155.

Triller, A., and H. Korn (1982) Transmission at a central inhibitory synapse: III. Ultrastructure of physiologically identified and stained terminals. J. Neurophysiol. 48: 708-736.

Triller, A., and H. Korn (1986) Variability of axonal arborizations hides simple rules of construction: A topological study from HRP intracellular injections. J. Comp. Neurol. 253: 500-513.
Triller, A., F. Cluzeaud, F. Pfeiffer, H. Betz, and H. Korn (1985) Distribution of glycine receptors at central synapses: An immunoelectron microscopy study. J. Cell Biol. 101: 683-688.

Triller, A., F. Cluzeaud, F. Pfeiffer, and H. Korn (1986) Distribution and transmembrane organisation of glycine receptors at central synapses: An immunocytochemical touch. In Molecular Aspects of Neurobiology, R. Levi-Montalcini, P. Calissano, E. R. Kandel, and A. Maggi, eds., pp. 101-105, Springer Verlag, Berlin.

Triller, A., T. Seitanidou, F. Cluzeaud, and H. Korn (1987a) Segregated versus overlapping glycinergic and GABAergic afferent systems at a vertebrate identified neuron. In Proceedings 45th Annual Meeting of the Electron Microscopy Society of America, G. W. Bailey, ed., pp. 688-689, San Francisco Press, San Francisco.

Triller, A., F. Cluzeaud, and H. Korn (1987b) Gamma-aminobutyric acid-containing terminals can be apposed to glycine receptors at central synapses. J. Cell Biol. 104: 947-956.

Tuttle, R., S. Masuko, and Y. Nakajima (1986) Freeze-fracture study of the large myelinated club ending synapse on the goldfish Mauthner cell: Special reference to the quantitative analysis of gap junctions. J. Comp. Neurol. 246: 202-211.

Werman, R., R. A. Davidoff, and M. H. Aprison (1967) Inhibition of motoneurons by iontophoresis of glycine. Nature 214: 681-683.

Werman, R., R. A. Davidoff, and M. H. Aprison (1968) Inhibitory action of glycine on spinal neurons in the cat. J. Neurophysiol. 31: $81-95$.

Werman, R. (1980) GABA modulates the glycine-receptor interaction in Mauthner cell allosterically. In Transmitters and their Receptors. U. Z. Littauer, Y. Dudai, I. Silman, V. I. Teichberg, and Z. Vogel, eds., pp. 393-404, Wiley, New York.

Wilkin, G. P., A. Csillag, R. Balazs, A. E. Kingsbury, J. E. Wilson, and A. L. Johnson (1981) Localization of high affinity $\left({ }^{3} \mathrm{H}\right)$ glycine transport sites in the cerebellar cortex. Brain Res. 216: 11-33.

Young, A. B., and S. H. Snyder (1973) Strychnine binding associatcd with glycine receptors of the central nervous system. Proc. Natl. Acad. Sci. USA 70: 2832-2836.

Young, A. B., and S. H. Snyder (1974) The glycine synaptic receptor: Evidence that strychnine binding is associated with the ionic conductance mechanism. Proc. Natl. Acad. Sci. USA 71: 4002-4005.

Zarbin, M. A., J. K. Wamsley, and M. J. Kuhar (1981) Glycine receptor: Light microscopic autoradiographic localization with $\left[{ }^{3} \mathrm{H}\right]$ strychnine. J. Neurosci. 1: 532-547.

Zottoli, S. J., and D.S. Faber (1980) An identifiable class of statoacoustic interneurons with bilateral projections in the goldfish medulla. Neuroscience 5: 1287-1302. 